DOI: https://doi.org/10.24867/13EF03Pavlica

\title{
KONTROLA KVALITETA OTISAKA OFSET ŠTAMPE U ŠTAMPARIJI POKRAJINSKE VLADE
}

\section{OFFSET PRESS PRINTING QUALITY CONTROL IN THE PROVINCIAL GOVERNMENT PRINTING OFFICE}

\author{
Milica Pavlica, Nemanja Kašiković, Rastko Milošević, Fakultet tehničkih nauka, Novi Sad
}

\begin{abstract}
Oblast - GRAFIČKO INŽENJERSTVO I DIZAJN
Kratak sadržaj - Rad se bavi kontrolom uzoraka štamparskih tabaka odštampanih na dve različite vrste papira iz različitih tiraža, sa ciljem da se utvrdi kvalitet štampe. Da bi se dobili potrebni rezultati korišćene su denzitometrijske $i$ spektrofotometrijske metode, pomoću kojih su ispitivane karakteristike otiska, a rezultati su potom upoređivani sa traženim, standardnim vrednostima kako bi se utvrdilo da li ima odstupanja $i$ da li su odstupanja u predviđenim dozvoljenim granicama.
\end{abstract}

Ključne reči: Kvalitet štampe, optička gustina, porast tonskih vrednosti, CIE $L^{*} a * b$, belina $i$ žutoća

\begin{abstract}
The paper deals with the control of samples of printing plates printed on two different types of paper from different circulations, with the aim of determining the quality of printing. The necessary results are obtained by densitometric and spectrophotometric methods, which explore the characteristics of the print, and the results are compared with required, standard values, to determine whether there are inconsistencies, and if they are within tolerable limits.
\end{abstract}

Keywords: Press quality, optical density, increase in tonal value, CIE $L^{*} a * b$, whiteness and yellowness

\section{UVOD}

Dinamičnim napretkom tehnologije poslednjih nekoliko decenija i zbog visokih zahteva tržišta, ofset štampa je došla do svog vrhunca i postala je jedna od najzastupljenijih tehnika štampe uopšte [1]. U toku štampanja parametre kvaliteta treba strogo i redovno kontrolisati. Temelj same kontrole štampe predstavljaju kontrolne merne trake [2]. Poželjno je na njima imati što više parametara, kako bi kontrola bila što potpunija. Uz njih se upotrebljavaju uređaji za merenje željenih parametara štampe, kao što su denzitometri, spektrofotometri i sl. Primenom ovih uređaja u realnim proizvodnim uslovima dobijaju se realni pokazatelji kvaliteta štampe, što je i cilj ovog rada.

\section{EKSPERIMENTALNI DEO}

U ovom eksperimentalnom delu, denzitrometrijskim i kolorimetrijskim metodama ispituje se kvalitet štampe

\section{NAPOMENA:}

Ovaj rad proistekao je iz master rada čiji mentor je bio dr Nemanja Kašiković, vanredni prof. biltena koji se sastoji iz četiri štamparska tabaka, pri čemu prvi tabak predstavlja korice, a kao materijal za štampu koristi se mat kunstdruk, premazni, gramature $150 \mathrm{~g} / \mathrm{m}^{2}$. Ostala tri tabaka predstavljaju unutrašnje tabake, a kao materijal za štampu koristi se bezdrvni papir, ofsetni, gramature $80 \mathrm{~g} / \mathrm{m}^{2}$. Proces štampe izvršen je tehnikom ofset štampe pomoću mašine Heidelberg Printmaster 74-2 u štampariji Pokrajinske vlade u Novom Sadu.

$\mathrm{Na}$ svim tabacima nalazi se kontrolna merna traka, sa poljima $5 \times 5 \mathrm{~mm}$, pogodnim za merenja. Na kontrolnoj mernoj traci se nalaze polja punog tona, polja za merenje porasta tonskih vrednosti od $20 \%, 40 \%, 60 \%$ i $80 \%$ tonske vrednosti i polja za merenje sivog balansa $u$ stopostotnoj vrednosti.

Prilikom kontrole kvaliteta korišćen je spektrofotometar SpectroDens proizvođača Techkon, pomoću kojeg je merena optička gustina, porast tonskih vrednosti, CIE Lab vrednosti, kao i belina i žutoća papira.

\section{REZULTATI MERENJA I DISKUSIJA}

Analizom ovih rezultata dobijena je procena kvaliteta reprodukcije u štampariji Pokrajinske vlade.

\subsection{Optička gustina}

Upoređujući izmerene optičke gustine na premaznim papirima sa preporučenim vrednostima iz tabele 1 može se zaključiti da nijedna boja nije u opsegu preporučenih vrednosti, odnosno ispod su preporučenih vrednosti, što se može jasno uočiti na grafiku 1 , gde su vrednosti za premazne papire prikazane kontinualnom linijom.

Tabela 1. Preporučene vrednosti optičke gustine punih tonova prema ISO 12647-2 standardu (2004)

\begin{tabular}{|c|c|c|c|c|}
\hline \multirow{2}{*}{ boja } & \multicolumn{2}{|c|}{ premazni papir } & \multicolumn{2}{c|}{ nepremazni papir } \\
\cline { 2 - 5 } & donja gr. & gornja gr. & donja gr. & gornja gr. \\
\hline K & 1.60 & 1.90 & 1.10 & 1.40 \\
\hline C & 1.35 & 1.55 & 0.90 & 1.10 \\
\hline M & 1.30 & 1.50 & 0.85 & 1.05 \\
\hline Y & 1.20 & 1.30 & 0.90 & 1.00 \\
\hline
\end{tabular}

Uzimajući u obzir toleranciju preporučenih vrednosti optičke gustine, izmerene vrednosti za magenta boju su najpribližnije opsegu, dok optičke vrednosti za žutu boju najviše odstupaju.

Kod tabaka štampanim na nepremaznim papirima primećuje se da su cijan i magenta boja na svih osam tabaka u opsegu preporučenih vrednosti.

Uzimajući u obzir toleranciju preporučenih vrednosti optičke gustine, izmerene vrednosti za crnu boju su u 
opsegu, sa pojedinim minimalnim odstupanjima na prvih pet tabaka, dok optičke vrednosti za žutu boju najviše odstupaju tj, ispod su donje granice, iako su te vrednosti minimalne.

Vrednosti za nepremazne papire su na grafiku 1 prikazane isprekidanom linijom.

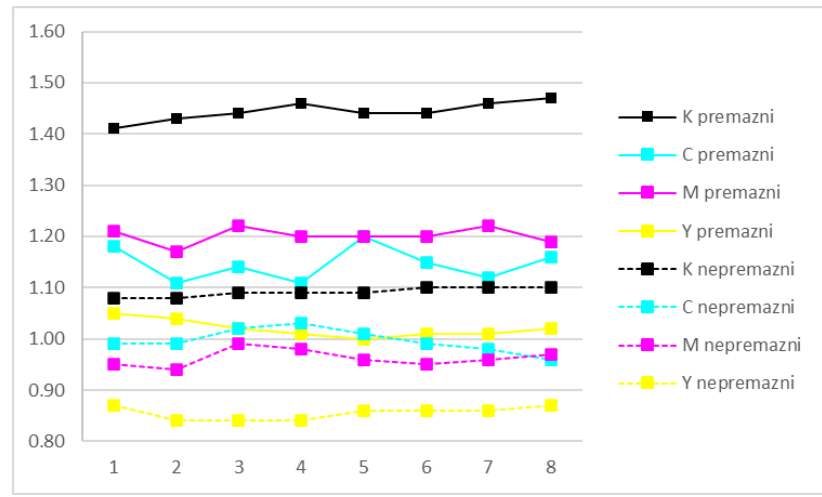

Grafik 1. Prosečne izmerene vrednosti optičke gustine

\subsection{Porast tonski vrednosti}

$\mathrm{Na}$ graficima 2 i 3 prikazane su izmerene vrednosti porasta tonskih vrednosti za $20 \%, 40 \%, 60 \%$ i $80 \%$ raster tonskih vrednosti.

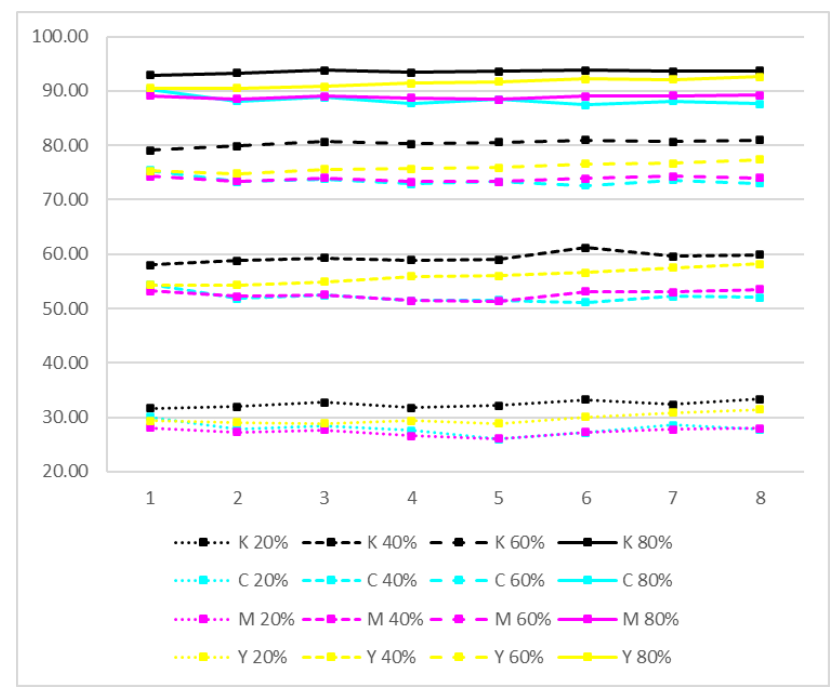

Grafik 2. Porast tonskih vrednosti za tabake štampane na premaznim papirima

Kod premaznih papira, polja crne boje su u porastu za oko $12 \%$ na poljima od $20 \%$, dok su na poljima od $40 \%$ i $60 \%$ dosta u porastu, za oko $20 \%$, i nisu konzistentne.

Porast od oko $13 \%$ primećuje se na poljima od $80 \%$. Primećuje se da su polja cijana u porastu za $8 \%$ na poljima od $20 \%$ i $80 \%$, i oko $13 \%$ na poljima od $40 \%$ i $60 \%$.

Kod polja magente, kao i kod cijana, vidi se porast za $8 \%$ na poljima od $20 \%$ i $80 \%$, i oko $13 \%$ na poljima od $40 \%$ i $60 \%$.

Porast od oko $10 \%$ na poljima od $20 \%$ i $80 \%$ uočava se kod polja žute boje, dok na poljima od 40\% i $60 \%$ taj porast iznosi oko $15 \%$.

Uglavnom, beleži se porast tonskih vrednosti od 6-20\% u zavisnosti od polja procesnih boja.

Polja crne boje su u porastu za oko $25 \%$ na poljima od $20 \%$ i $60 \%$, i nisu konzistentna.
Porast od oko $30 \%$ primećuje se na poljima od $40 \%$, dok kod polja od $80 \%$ taj porast iznosi oko $15 \%$. Primećuje se da su polja cijana u porastu za oko $16 \%$ na poljima od $20 \%$, i za oko $13 \%$ na poljima od $80 \%$, dok je kod na poljima od $40 \%$ i $60 \%$ taj porast za oko $21 \%$.

Kod polja magente, kao i kod cijana, prisutan je porast za oko $16 \%$ na poljima od $20 \%$, i za oko $13 \%$ na poljima od $80 \%$, dok je kod na poljima od $40 \%$ i $60 \%$ taj porast za oko $21 \%$.

Porast od oko $21 \%$ na poljima od $20 \%$ uočava se kod polja žute boje, dok na poljima od $40 \%$ i $60 \%$ taj porast iznosi oko $27 \%$, i $14 \%$ na poljima od $80 \%$.

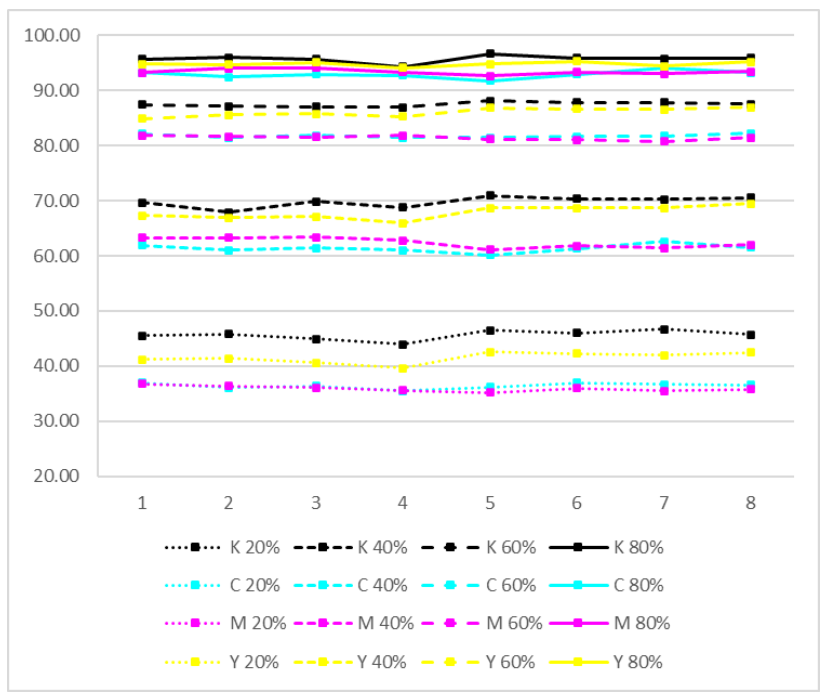

Grafik 3. Porast tonskih vrednosti za tabake štampane na nepremaznim papirima

\subsection{CIE Lab vrednosti}

U tabelama 2 i 3 prikazane su Lab vrednosti za oba materijala kao i razlika u boji $\Delta \mathrm{E}$, dok su u tabeli 4 date standardne Lab vrednosti.

Posmatrajući premazne papire, vrednost svetline L je kod crne, cijana i magente veća od standardne vrednosti, što znači da su te boje svetlije nego što bi trebalo da budu. $\mathrm{Na}$ to ukazuje i njihov $\Delta \mathrm{L}$ koji je kod crne, cijana i magente pozitivan.

Vrednost svetline L je kod žute boje manji od standardne vrednosti, dok je $\Delta \mathrm{L}$ negativan, što pokazuje da je boja tamnija.

Tabela 2. Prosečne izmerene Lab vrednosti za tabake stampane na premaznim papirima

\begin{tabular}{|c|c|c|c|c|}
\hline \multicolumn{5}{|c|}{ Crna } \\
\hline & $\mathrm{L}$ & $\mathrm{a}$ & $\mathrm{b}$ & $\Delta \mathrm{E}$ \\
\hline 1 & 21.05 & -1.33 & -1.63 & 6.05 \\
\hline 2 & 20.50 & -1.21 & -1.63 & 6.17 \\
\hline 3 & 20.24 & -1.22 & -1.65 & 6.19 \\
\hline 4 & 19.78 & -1.17 & -1.52 & 6.25 \\
\hline 5 & 20.04 & -1.18 & -1.55 & 6.21 \\
\hline 6 & 20.16 & -1.13 & -1.58 & 6.29 \\
\hline 7 & 20.00 & -1.11 & -1.42 & 6.35 \\
\hline 8 & 19.57 & -1.06 & -1.30 & 6.35 \\
\hline sr. vr. & 20.17 & -1.18 & -1.53 & 6.23 \\
\hline$\Delta$ & 5.92 & -1.18 & -1.53 & \\
\hline
\end{tabular}




\begin{tabular}{|c|c|c|c|c|}
\hline \multicolumn{5}{|c|}{ Cijan } \\
\hline & $\mathrm{L}$ & $\mathrm{a}$ & $\mathrm{b}$ & $\Delta \mathrm{E}$ \\
\hline 1 & 58.80 & -31.71 & -42.87 & 5.17 \\
\hline 2 & 60.51 & -31.59 & -39.91 & 5.22 \\
\hline 3 & 59.98 & -31.71 & -40.38 & 5.51 \\
\hline 4 & 60.87 & -31.54 & -39.70 & 5.63 \\
\hline 5 & 60.91 & -31.46 & -39.71 & 5.72 \\
\hline 6 & 60.52 & -31.66 & -39.88 & 5.77 \\
\hline 7 & 60.71 & -31.53 & -39.63 & 5.88 \\
\hline 8 & 60.47 & -31.62 & -39.82 & 5.84 \\
\hline sr. vr. & 60.35 & -31.60 & -40.24 & 5.59 \\
\hline$\Delta$ & 3.13 & 3.24 & 3.31 & \\
\hline \multicolumn{5}{|c|}{ Magenta } \\
\hline & $\mathrm{L}$ & $a$ & $\mathrm{~b}$ & $\Delta \mathrm{E}$ \\
\hline 1 & 46.89 & 61.46 & -7.63 & 7.89 \\
\hline 2 & 47.66 & 60.65 & -8.55 & 7.98 \\
\hline 3 & 46.70 & 61.74 & -7.22 & 8.14 \\
\hline 4 & 47.22 & 61.40 & -7.65 & 8.16 \\
\hline 5 & 47.25 & 61.17 & -7.96 & 8.26 \\
\hline 6 & 47.32 & 61.32 & -8.12 & 8.39 \\
\hline 7 & 46.97 & 61.62 & -7.44 & 8.46 \\
\hline 8 & 47.42 & 61.20 & -8.03 & 8.54 \\
\hline sr. vr. & 47.18 & 61.32 & -7.82 & 8.23 \\
\hline$\Delta$ & 2.86 & -6.91 & -3.43 & \\
\hline \multicolumn{5}{|c|}{ Žuta } \\
\hline & $\mathrm{L}$ & $a$ & $\mathrm{~b}$ & $\Delta \mathrm{E}$ \\
\hline 1 & 83.13 & -2.03 & 91.04 & 24.01 \\
\hline 2 & 83.39 & -2.31 & 90.54 & 24.15 \\
\hline 3 & 83.76 & -2.51 & 90.00 & 24.19 \\
\hline 4 & 83.65 & -2.56 & 90.33 & 24.27 \\
\hline 5 & 83.53 & -2.61 & 90.34 & 24.36 \\
\hline 6 & 83.53 & -2.56 & 90.87 & 24.49 \\
\hline 7 & 83.74 & -2.33 & 90.99 & 24.68 \\
\hline 8 & 83.43 & -2.24 & 91.41 & 24.91 \\
\hline sr. vr. & 83.52 & -2.39 & 90.69 & 24.38 \\
\hline$\Delta$ & -2.32 & -0.86 & -24.25 & \\
\hline
\end{tabular}

Najprimetnija razlika u svetlini $\Delta \mathrm{L}$ je kod cijan boje, dok razlike u svetlini $\Delta \mathrm{L}$ kod crne, magente i žute odstupaju za nekoliko jedinica.

Što se tiče hromatičnosti, izmerene prosečne vrednosti $\Delta \mathrm{a}$ kod crne boje iznosi -1.18, što znači da boja na a osi vuče ka zelenoj boji, dok $\Delta \mathrm{b}$ iznosi -1.53 , tako da boja na b osi vuče ka plavoj boji.

Shodno opisanim razlikama ponaša se i $\Delta \mathrm{E}$ vrednost koja pokazuju dosta veliku razliku u boji.

Kod cijan boje, izmerena prosečna vrednost $\Delta$ a je 3.24, gde boja na a osi vuče ka crvenoj boji, a na b osi vuče ka žutoj boji, pošto je izmerena prosečna vrednost $\Delta \mathrm{b}$ je 3.31 .

$\mathrm{U}$ odnosu na ostale boje, $\Delta \mathrm{E}$ kod cijana ima najmanju vrednost.

Kod magenta boje, izmerena prosečna vrednost $\Delta \mathrm{a}$ je 6.91, gde boja na a osi vuče ka zelenoj boji, a na b osi vuče ka plavoj boji, pošto je izmerena prosečna vrednost $\Delta \mathrm{b}$ je -3.43 .

Kada je žuta boja u pitanju, izmerena prosečna vrednost $\Delta \mathrm{a}$ iznosi $-0,86$, što znači da boja na a osi vuče ka zelenoj boji, dok $\Delta$ b iznosi $-24,25$, tako da boja na b osi vuče ka zelenoj boji.

$\mathrm{U}$ ovom slučaju $\Delta \mathrm{E}$ kod žute boje beleži najveću vrednost i ona kao takva ne bi trebalo da uđe u opseg tolerancije.

Kod svih osam tabaka nepremaznog papira, vrednost svetline L je kod sve četiri boje manja od standardne vrednosti, što znači da su te boje tamnije nego što bi trebalo da budu. Na to ukazuje i njihov $\Delta \mathrm{L}$ koji je kod crne, cijana i magente pozitivan. dok je kod žute boje $\Delta \mathrm{L}$ negativan, ali vrlo malo.

Tabela 3. Prosečne izmerene Lab vrednosti za tabake štampane na nepremaznim papirima

\begin{tabular}{|c|c|c|c|c|}
\hline \multicolumn{5}{|c|}{ Crna } \\
\hline & $\mathrm{L}$ & $a$ & $b$ & $\Delta \mathrm{E}$ \\
\hline 1 & 30.42 & 0.19 & 0.43 & 9.11 \\
\hline 2 & 30.24 & 0.28 & 0.43 & 9.22 \\
\hline 3 & 30.02 & 0.24 & 0.47 & 9.33 \\
\hline 4 & 29.99 & 0.28 & 0.47 & 9.42 \\
\hline 5 & 29.79 & 0.24 & 0.45 & 9.51 \\
\hline 6 & 29.75 & 0.28 & 0.52 & 9.63 \\
\hline 7 & 30.11 & 0.28 & 0.47 & 9.74 \\
\hline 8 & 29.69 & 0.25 & 0.34 & 9.82 \\
\hline sr. vr. & 30.00 & 0.26 & 0.45 & 9.47 \\
\hline$\Delta$ & 9.45 & -0.62 & 0.11 & \\
\hline \multicolumn{5}{|c|}{ Cijan } \\
\hline & $\mathrm{L}$ & $\mathrm{a}$ & $b$ & $\Delta \mathrm{E}$ \\
\hline 1 & 56.56 & -22.48 & -39.01 & 7.92 \\
\hline 2 & 57.67 & -22.69 & -37.87 & 7.96 \\
\hline 3 & 56.04 & -22.49 & -39.26 & 8.13 \\
\hline 4 & 55.82 & -22.49 & -39.50 & 8.22 \\
\hline 5 & 56.63 & -22.60 & -38.69 & 8.31 \\
\hline 6 & 56.31 & -22.49 & -39.13 & 8.36 \\
\hline 7 & 56.43 & -22.50 & -38.67 & 8.42 \\
\hline 8 & 56.92 & -22.64 & -38.77 & 8.46 \\
\hline sr. vr. & 56.55 & -22.55 & -38.86 & 8.22 \\
\hline$\Delta$ & 4.24 & 3.87 & 5.89 & \\
\hline \multicolumn{5}{|c|}{ Magenta } \\
\hline & $\mathrm{L}$ & $\mathrm{a}$ & $\mathrm{b}$ & $\Delta \mathrm{E}$ \\
\hline 1 & 49.11 & 50.43 & -2.70 & 10.65 \\
\hline 2 & 50.09 & 49.58 & -3.85 & 10.71 \\
\hline 3 & 48.96 & 51.07 & -2.85 & 10.72 \\
\hline 4 & 49.17 & 51.03 & -3.06 & 10.82 \\
\hline 5 & 49.98 & 50.20 & -4.05 & 10.84 \\
\hline 6 & 49.93 & 50.35 & -4.09 & 10.93 \\
\hline 7 & 49.51 & 50.67 & -3.36 & 10.96 \\
\hline 8 & 50.02 & 50.44 & -3.80 & 10.95 \\
\hline sr. vr. & 49.60 & 50.47 & -3.47 & 10.82 \\
\hline$\Delta$ & 1.46 & -10.27 & -3.06 & \\
\hline \multicolumn{5}{|c|}{ Žuta } \\
\hline & $\mathrm{L}$ & $a$ & $b$ & $\Delta \mathrm{E}$ \\
\hline 1 & 80.60 & 1.23 & 73.90 & 20.49 \\
\hline 2 & 81.23 & 0.53 & 72.34 & 20.58 \\
\hline 3 & 81.54 & 0.73 & 73.63 & 20.69 \\
\hline 4 & 81.53 & 0.88 & 73.77 & 20.75 \\
\hline 5 & 81.01 & 1.55 & 75.22 & 20.74 \\
\hline 6 & 81.11 & 1.65 & 75.63 & 20.89 \\
\hline 7 & 80.96 & 0.86 & 73.38 & 20.95 \\
\hline 8 & 80.84 & 1.33 & 74.89 & 21.04 \\
\hline sr. vr. & 81.10 & 1.09 & 74.10 & 20.77 \\
\hline$\Delta$ & -1.73 & 1.17 & -20.66 & \\
\hline
\end{tabular}

Najprimetnija razlika u svetlini $\Delta \mathrm{L}$ je kod crne boje, zatim kod cijan boje, dok razlike u svetlini $\Delta \mathrm{L}$ kod magente i žute odstupaju skoro za dve jedinice.

Kada je hromatičnost u pitanju, izmerene prosečne vrednosti $\Delta \mathrm{a}$ kod crne boje iznosi - 0.62 , što znači da boja na a osi vuče ka zelenoj boji, dok $\Delta \mathrm{b}$ iznosi -0.11, tako da boja na b osi vuče ka žutoj boji.

$\mathrm{Na}$ osnovu tih razlika, ponaša se i $\Delta \mathrm{E}$ vrednost koja pokazuje veliku razliku u boji.

Kod cijan boje, izmerena prosečna vrednost $\Delta$ a je 3.87, gde boja na a osi vuče ka crvenoj boji, a na b osi vuče ka žutoj boji, pošto je izmerena prosečna vrednost $\Delta b$ je 5.89. Posmatrajući ostale boje, $\Delta \mathrm{E}$ kod cijana ima najmanju vrednost. 
Kod magenta boje, izmerena prosečna vrednost $\Delta \mathrm{a}$ je 10.27, gde boja na a osi vuče ka zelenoj boji, a na b osi vuče ka plavoj boji, pošto je izmerena prosečna vrednost $\Delta \mathrm{b}$ je -3.06 .

Što se žuta boje tiče, izmerena prosečna vrednost $\Delta \mathrm{a}$ iznosi 1.17 , što znači da boja na a osi vuče ka crvenoj boji, dok $\Delta$ b iznosi -20.66 , tako da boja na b osi vuče ka zelenoj boji.

$\mathrm{U}$ ovom slučaju $\Delta \mathrm{E}$ kod žute boje beleži najveću vrednost i ona kao takva ne bi trebalo da se toleriše.

Tabela 4. Standardne Lab vrednosti za mat premazni $i$ nepremazni papir

\begin{tabular}{|c|c|c|c|c|c|c|}
\hline \multirow{2}{*}{ boja } & \multicolumn{2}{|c|}{ premazni papiri } & \multicolumn{3}{|c|}{ nepremazni papiri } \\
\cline { 2 - 7 } & $\mathrm{L}$ & $\mathrm{a}$ & $\mathrm{b}$ & $\mathrm{L}$ & $\mathrm{a}$ & $\mathrm{b}$ \\
\hline $\mathrm{K}$ & 16 & 0 & 0 & 31 & 1 & 1 \\
\hline $\mathrm{C}$ & 54 & -36 & -49 & 58 & -25 & -43 \\
\hline $\mathrm{M}$ & 46 & 72 & -5 & 54 & 58 & -2 \\
\hline $\mathrm{Y}$ & 87 & -6 & 90 & 86 & -4 & 75 \\
\hline
\end{tabular}

\subsection{Belina i žutoća}

Indeksi beline prikazuju koliko je papir beo, tj. što je veća vrednost koja se dobije merenjem, to papir karakteriše veća belina. Iz tabele 5, koja je dobijena merenjem može se zaključiti da nepremazni papir karakteriše izražena belina, dok je premazni papir manje beo. Izmerene vrednosti su ujednačene i ne variraju previše, što znači da je belina na papirima uglavnom ujednačena.

Tabela 5. Prosečne izmerene vrednosti indeksa beline kod premaznih i nepremaznih papira

\begin{tabular}{|c|c|c|}
\hline belina & premazni & nepremazni \\
\hline 1 & 101.94 & 111.24 \\
\hline 2 & 101.43 & 109.22 \\
\hline 3 & 102.27 & 110.11 \\
\hline 4 & 102.08 & 108.76 \\
\hline 5 & 101.78 & 107.59 \\
\hline 6 & 102.52 & 109.62 \\
\hline 7 & 100.83 & 111.35 \\
\hline 8 & 101.62 & 110.11 \\
\hline
\end{tabular}

Ono što karakteriše žutoću jeste udeo žute boje u papiru. Vrednosti koje su veće od nule pokazuju da je papir žući, a manje vrednosti koje idu od nule ka negativnim brojevima pokazuju da papir ima veći udeo plave boje. Srednje vrednosti izmerene na tabacima prikazane su u tabeli 6 .

Tabela 6. Prosečne izmerene vrednosti indeksa žutoće kod premaznih i nepremaznih papira

\begin{tabular}{|c|c|c|}
\hline žutoća & premazni & nepremazni \\
\hline 1 & -8.09 & -13.25 \\
\hline 2 & -7.83 & -13.31 \\
\hline 3 & -8.25 & -13.25 \\
\hline 4 & -8.03 & -13.13 \\
\hline 5 & -7.98 & -12.94 \\
\hline 6 & -8.17 & -13.25 \\
\hline 7 & -7.88 & -13.18 \\
\hline 8 & -7.93 & -13.50 \\
\hline
\end{tabular}

$\mathrm{Na}$ osnovu prosečnih vrednosti iz tabele, podloge koje ove karakteristike opisuju imaju više udela plave boje, i ne karakteriše ih izražena žutoća, pošto su sve vrednosti negativne, a indeksi se kreću oko -8.02 za premazne odnosno -13.23 za nepremazne, bezdrvne ofset tabake.

\section{ZAKLJUČAK}

Prema rezultatima merenja optičke gustine kod premaznih papira, može se zaključiti da nijedna boja nije u opsegu preporučenih vrednosti, odnosno ispod su preporučenih vrednosti, iako rezultati merenja ukazuju na to da su optičke gustine polja punih tonskih vrednosti na pojedinačnim tabacima uglavnom ujednačene, duž tabaka. Kod nepremaznih papira, sve boje su u opsegu preporučenih vrednosti, mada, na nekim tabacima, može se primetiti minimalno odstupanje.

Kod premaznih papira i nepremaznih, beleži se porast tonskih vrednosti od 6-27\% u zavisnosti od polja procesnih boja, što je daleko više iznad preporučenih vrednosti.

Kod merenja CIE Lab vrednosti utvrđeno je da su boje na premaznim tabacima nešto svetlije nego što je to standardom predviđeno, dok je kod nepremaznih tabaka obrnuto, što znači da su te boje tamnije nego što bi trebalo da budu.

Polja sivog balansa i na premaznim i na nepremaznim tabacima pokazuju dominantnu cijan boju u odnosu na magentu i žutu, koje imaju nešto niže vrednosti.

Tabaci koji se koriste u štampi sačinjeni su od kvalitetnog materijala, i karakteriše ih visoka i ujednačena belina, pa predstavljaju odgovarajuću podlogu za štampu i odgovarajući materijal za prikaz slika i teksta, što su pokazala merenja beline i žutoće.

Kada se vizuelno pogleda otisak, ne primećuje se neka veća devijacija u reprodukciji boja, zagušenje ili neki nedostatak. Tamnije slike su isto jasne i pregledne kao i svetlije, a tekst savršeno čitljiv.

\section{LITERATURA}

[1] Novaković D., Pavlović Ž., Kašiković N. (2011) Tehnike štampe, praktikum za vežbe, Novi Sad, FTN Izdavaštvo.

[2] Novaković D., Pavlović Ž., Karlović I., Pešterac Č. (2008) Reprodukciona tehnika, priručnik za vežbe, Novi Sad, FTN Izdavaštvo.

\section{Adrese autora za kontakt:}

Milica Pavlica, milica.pavlica@yahoo.com dr Nemanja Kašiković, knemanja@uns.ac.rs dr Rastko Milošević, rastko.m@uns.ac.rs Grafičko inženjerstvo i dizajn, FTN, Novi Sad 